\title{
Aroma characterization of two melon cultivars using headspace-solid phase microextraction combined with gas chromatography-mass spectrometry
}

\author{
Mi Tang, Jian Ren, Weishun Cheng, Ye Liu, Na Zhang, Hongxia Zeng, Yuhua \\ Li, Yuhong Sun*
}

Institute of Crop Science, Wuhan Academy of Agricultural Science and Technology, Wuhan 430345, China

* Corresponding author. E-mail address: tommy512@163.com

Keywords: melon, aroma, headspace-solid phase microextraction, gas chromatography-mass spectrometry.

\begin{abstract}
The aroma compounds of melon fruits play a crucial role in commercial value. Aroma characterization of the 'Flavor No. 4' and 'Xuelihong' melon was detected using headspace-solid phase microextraction (HS-SPME) combined with gas chromatography-mass spectrometry (GC-MS). The results suggested that esters were the main aroma compositions in two melon cultivars, as more than $70 \%$ of the total volatile compounds yield, and the remains were alcohols, aldehydes, ketones, and others. Acetic acid, phenylmethyl ester (34.39\%; 7.64\% ), and ethyl acetate (21.37\%; 59.18\%), presented as major compounds in the 'Flavor No. 4' and 'Xuelihong'.
\end{abstract}

\section{Introduction}

Melon fruits are diverse in shape and size, in rind and flesh color, and in flesh texture, and flavor (Burger et al, 2006). Aroma is one of the most important factors in fruit quality and consumer preference. Around 240 compounds have been identified in climacteric types such as Galia or Cantaloupe melons, about half of them are esters, and most of the remaining components are sulfur-derived compounds, aldehydes and alcohols, (Fallik et al., 2001; Kourkoutas et al., 2006). In contrast, non-climacteric types show lower levels of total aroma compounds, and 42 compounds identified in Hami melons according to Moshonas et al. (1993).

Solid-phase microextraction (SPME) is a solvent-free, simple, inexpensive, rapid, and versatile method for the extraction of volatile compounds, and it was utilized to study flavor volatile profiles in melon fruits (Beaulieu and Grimm, 2001; Beaulieu, 2006).

There is an ongoing need for melon improvement in fruit qualities to better meet market demands. 'Flavor No.4' melon, is a novel cultivar which tastes both sour and sweet, and the profile of the fruit aroma is knew little to us, so the aim of this study was to analyze the volatile constituents of this novel melon using SPME with gas chromatography-mass spectrometry (GC-MS).

\section{Materials and methods}

\section{Plant material}

The fresh 'Flavor No. 4' (a novel melon cultivar) and 'Xuelihong' (a traditional melon cultivar) fruits were collected at Wuhan, central China (latitude $30^{\circ} 27^{\prime} \mathrm{N}$, longitude $114^{\circ} 20^{\prime} \mathrm{E}$, altitude 22 $\mathrm{m})$. in Hubei province of China at April in 2015. The plants were cultivated in a plastic greenhouse. Plants were grown in a 1:1:1 (v/v/v) mixture of solar-disinfected peat, vermiculite, and perlite, with regular applications of soluble fertilizer. Plants were trained to a single main vine. Flowers were hand-pollinated and fruit load was limited to one fruit per plant. Plants were set in a completely randomized design. Fruits of two varieties were harvested when got the commercial mature.

\section{SPME}

Fresh melons were peeled, cut, and the seeds extracted. The fruit flesh was chopped into small 
pieces and homogenized, and then about $25 \mathrm{~g}$ were placed into a $60 \mathrm{~mL}$ vial immediately. Vials were hermetically closed by a teflon/silicone septum, and the SPME syringe was inserted into the vial for equilibrated at $80{ }^{\circ} \mathrm{C}$ for $30 \mathrm{~min}$. The analytes desorption from the fibre coating was made in the injector port of GC-MS at $250{ }^{\circ} \mathrm{C}$ for $4 \mathrm{~min}$.

\section{GC-MS analysis}

A GC-MS Finnigan Trace 2000 equipped with a RTX-5MS column $(30 \mathrm{~m} \times 0.25 \mathrm{~mm}$ ) was used to identify the volatile compounds. Helium $(1 \mathrm{~mL} / \mathrm{min})$ was used as carrier gas in a constant flow. The injector temperature was $250{ }^{\circ} \mathrm{C}$, and set for splitless injection. The oven temperature was set at $40{ }^{\circ} \mathrm{C}$ for $2 \mathrm{~min}$, and then increased to $50{ }^{\circ} \mathrm{C}$ at a rate of $10^{\circ} \mathrm{C} / \mathrm{min}$ for $5 \mathrm{~min}$, and then increased to $250{ }^{\circ} \mathrm{C}$ at a rate of $10{ }^{\circ} \mathrm{C} / \mathrm{min}$ for $3 \mathrm{~min}$. The mass range was collected from 40 to $650 \mathrm{~m} / \mathrm{z}$, with electron energy of $70 \mathrm{eV}$. The total ion chromatogram obtained was auto-integrated by ChemStation and the constituents were identified by comparing the retention times with those of authentic compounds and the spectral data obtained from the Mainlib and NIST libraries, and published literatures.

\section{Results}

\section{Volatile compounds analysis}

GC-MS detected and identified over 100 volatile compounds in all (data not shown). Esters were the main aroma compositions in both melons, as more than $70 \%$ of the total volatile compounds yield, and the remains were alcohols, aldehydes, acids, ketoses, and others. But, esters, and ketoses contents in 'Flavor No. 4' (73.39\%; 0.14\%) were lower than that in 'Xuelihong' (80.38\%; 0.43\%), in contrast, alcohols, aldehydes, and acids contents (7.2\%; $2.99 \%$; $1.03 \%)$ in 'Flavor No. 4' was higher than that in 'Xuelihong' (1.73\%; 0.45\%; 0.25\%).

Table 1 revealed the main identified volatiles compounds and relative contents in 'Flavor No.4' and 'Xuelihong'. There were distinct qualitative and quantitative differences in aromatic volatiles in two melon cultivars, like as esters (Acetic acid, phenylmethyl ester; Ethyl Acetate; Acetic acid, 2-phenylethyl ester; et al), alcohols [3-Nonen-1-ol, (E)-, Benzyl Alcohol, (tert-Hexadecanethiol, et al], aldehydes [Heptanal; Hexanal; Benzaldehyde; ], acids [2-Amino-5-methylbenzoic acid; Dodecanoic acid, 3-hydroxy-; Phthalamic acid] and other compounds, as sulfur-derived compounds (Disulfide, ethyl hexyl).

Acetic acid, phenylmethyl ester (34.39\%; 7.64\%) and Ethyl Acetate (21.37\%; 59.18\%) were the higher content esters in both 'Flavor No. 4' and 'Xuelihong'. However, higher content of 1,4-Dioxan-2-o was found in 'Flavor No.4' (4.15\%) than in 'Xuelihong' (ND). Referring to aldehydes and acids, 'Flavor No.4', contained significantly higher relative contents of Heptanal (0.28\%), Hexanal (1.01\%) and Benzaldehyde (1.61\%) and 5-Octadecenal (0.06\%) than 'Xuelihong' (ND), while lower contents of Nonanal (ND) and 10-Octadecenal (ND) than 'Xuelihong' (0.41\%; 0.04\%).

\section{Discussion}

The formation of fruits is often accompanied by profound changes in their chemical composition. Sensory quality of fruit is largely determined by its sugar and organic acid levels, in addition to the volatile aromatic components. In this study, 'Flavor No. 4' and 'Xuelihong' exhibited distinct appearances. The variation in aroma profile depends on the high diversity of melon cultivars. The climacteric senescent fruit could be discriminated from the non-climacteric fruit by 11 compounds of the profile, mainly benzyl acetate, hexanal and pentanal (Obando-Ulloa et al., 2009). Volatile compounds also differ in different sections of the fruit. The quantitative distribution of volatile compounds in Queen Anne's pocket melon showed that the levels of volatiles in skin were significantly higher than those observed in pulp (Aubert and Pitrat, 2006). Eugenol, thioether esters, and lactones were thought to contribute significantly to the unique aroma of the pocket melon. And Lewinsohn et al. (2008) reported that sesquiterpenes were present mainly in the rinds of climacteric varieties, and generally absent in non-climacteric varieties. 
Table 1 Main volatiles compounds and relative contents (\%) in two cultivars.

\begin{tabular}{|c|c|c|}
\hline Components Name & Flavor No. 4 & Xuelihong \\
\hline \multicolumn{3}{|l|}{ Esters } \\
\hline Acetic acid, phenylmethyl ester & 34.39 & 7.64 \\
\hline Ethyl Acetate & 21.37 & 59.18 \\
\hline Acetic acid, 2-phenylethyl ester & 2.2 & 0.52 \\
\hline E-8-Methyl-9-tetradecen-1-ol acetate & 1.64 & 2.03 \\
\hline Dasycarpidan-1-methanol, acetate (ester) & 0.90 & 0.23 \\
\hline 1-Butanol, 2-methyl-, acetate & 0.35 & 0.02 \\
\hline E-10,13,13-Trimethyl-11-tetradecen-1-ol acetate & 0.32 & 0.19 \\
\hline i-Propyl 11,12-methylene-octadecanoate & 0.11 & 0.05 \\
\hline Benzaldehyde, 2,4-bis(trimethylsiloxy)- & 0.11 & 2.46 \\
\hline 7-Methyl-Z-tetradecen-1-ol acetate & 0.08 & 0.02 \\
\hline \multicolumn{3}{|l|}{ Alcohols } \\
\hline 3-Nonen-1-ol, (E)- & 0.75 & 0.87 \\
\hline Benzyl Alcohol & 0.38 & 0.46 \\
\hline tert-Hexadecanethiol & 0.05 & 0.04 \\
\hline 1,4-Dioxan-2-ol & 4.15 & ND \\
\hline \multicolumn{3}{|l|}{ Aldehydes } \\
\hline Heptanal & 0.28 & ND \\
\hline Hexanal & 1.01 & ND \\
\hline Benzaldehyde & 1.64 & ND \\
\hline 5-Octadecenal & 0.06 & ND \\
\hline Nonanal & ND & 0.41 \\
\hline 10-Octadecenal & ND & 0.04 \\
\hline \multicolumn{3}{|l|}{ Acids } \\
\hline 2-Amino-5-methylbenzoic acid & 0.45 & ND \\
\hline Dodecanoic acid, 3-hydroxy- & 0.21 & ND \\
\hline Phthalamic acid & 0.17 & 0.11 \\
\hline trans-2-Hexadecenoic acid & 0.07 & ND \\
\hline Heneicosanoic acid & 0.04 & ND \\
\hline 2-Bromotetradecanoic acid & 0.06 & ND \\
\hline 5-Benzoylpentanoic acid & 0.03 & ND \\
\hline Pterin-6-carboxylic acid & ND & 0.05 \\
\hline n-Decanoic acid & ND & 0.09 \\
\hline \multicolumn{3}{|l|}{ Ketones } \\
\hline 2,2,7,7-Tetramethyltricyclo[6.2.1.0(1,6)]undec-4-en-3-one & 0.14 & ND \\
\hline 2,5,5-Trimethylcyclohex-2-enone & ND & 0.14 \\
\hline Bicyclo[2.2.1]heptan-2-one, 1,7,7-trimethyl-, (1R)- & ND & 0.09 \\
\hline 4-Hydroxy-2,4,5-trimethyl-2,5-cyclohexadien-1-one & ND & 0.17 \\
\hline 4,6-Dimethyl(1H)pyrid-2-one, -3-(3-nitrophenylmethylenamino) & ND & 0.03 \\
\hline \multicolumn{3}{|l|}{ Others } \\
\hline Disulfide, ethyl hexyl & 0.23 & ND \\
\hline l-Gala-l-ido-octose & 0.78 & 0.02 \\
\hline 3-O-Benzyl-d-glucose & 0.03 & ND \\
\hline d-Glycero-d-tallo-heptose & ND & 0.02 \\
\hline Azulene & ND & 0.51 \\
\hline Dodecane & ND & 0.14 \\
\hline Naphthalene, 2-methyl- & ND & 0.02 \\
\hline Acenaphthene & ND & 0.04 \\
\hline Benzene, 1,2,4-trichloro- & ND & 0.09 \\
\hline
\end{tabular}

\section{ND: No detected.}

Results from this study revealed that Acetic acid, phenylmethyl ester and Ethyl Acetate present as major compounds in the pulp of 'Flavor No. 4' and 'Xuelihong' fruit, which were reported in other melon cultivars in previous research. However, sulfur-containing compounds, which also have low odor thresholds and are believed to play an important role in the overall aroma profile of melon fruit (Wyllie and Leach, 1992), were detected in this study in 'Flavor No.4'.

In fact, the aroma profile at harvest was a good tool to discriminate melon varieties. Several compounds can be used as biomarkers of the physiological behavior, but further studies about 
aroma, including the aroma precursors and enzymatic activities associated with aroma formation in melon, are required. This will help us understand and further characterize the biochemical, physiological and environmental parameters involved in the formation of aroma compounds in melons, and perhaps allow us to monitor the formation of volatiles in melon cultivars.

\section{Acknowledgement}

This work is funded by the Young Talents Project of the Wuhan Academy of Agricultural Science and Technology (QNYC201302), and the National Natural Science Foundation of China (31301796).

\section{References}

[1] Aubert, C. and Pitrat, M. 2006. Volatile compounds in the skin and pulp of Queen Anne's pocket melon, J. Agric. Food Chem. 54:8177-8182.

[2] Beaulieu, J.C. 2006. Volatile changes in cantaloupe during growth, maturation, and in stored fresh-cuts prepared from fruit harvested at various maturities. J. Amer. Soc. Hort. Sci.131:127-139.

[3] Beaulieu, J.C. and Grimm, C.C. 2001. Identification of volatile compounds in cantaloupe at various developmental stages using solid phase microextraction. J. Agric. Food Chem. 49:1345-1352.

[4] Burger, Y., Sa’ar, U., Paris, H.S., Lewinsohn, E., Katzir, N., Tadmor, Y., Schaffer, A.A. 2006. Genetic variability as a source of new valuable fruit quality traits in Cucumis melo. Israel J. Plant Sci. 54: 233-242.

[5] Fallik, E., Alkali-Tuvia, S., Horev, B., Copel, A., Rodov, V., Aharoni, Y., Ulrich, D. and Schulz, H. 2001. Characterisation of 'Galia' melon aroma by GC and mass spectrometric sensor measurements after prolonged storage. Postharvest Biol. Technol. 22:85-91.

[6] Kourkoutas, D., Elmore, J.S. and Mottram, D.S., 2006. Comparison of volatile compositions and flavour properties of cantaloupe, Galia and honeydew muskmelons. Food Chem. 97:95-102.

[7] Lewinsohn, E., Portnoy, V., Benyamini, Y., Bar, E., Harel-Beja, R., Gepstein, S., Giovannoni, J.J., Schaffer, A.A., Burger, Y., Tadmor, Y. and Katzir, N. 2008. Sesquiterpene aroma biosynthesis in melon (Cucumis melo) rinds, Proceedings of the IXth EUCARPIA Meeting on Genetics and Breeding of Cucurbitaceae. Pitrat, M. (ed): 249-256.

[8] Moshonas, M.G., Shaw, P.E., Baldwin, E.A. and Yuen,W. 1993. Volatile and nonvolatile components in Hami melon (Cucumis melo L.). Lebensm. Wiss. Technol. 26:577-580.

[9] Obando-Ulloa, J.M., Nicolai, B., Lammertyn, J., Bueso, M.C., Monforte, A.J.and Fernández-Trujillo, J. P. 2009. Aroma volatiles associated with the senescence of climacteric or non-climacteric melon fruit, Postharvest Bio. Technol. 52:146-155.

[10] Saftner, R., Abbott, J.A., Lester, G. and Vinyard, B. 2006. Sensory and analytical comparison of orange-fleshed honeydew to cantaloupe and green-fleshed honeydew for fresh-cut chunks. Postharvest Biol. Technol. 42:150-160.

[11] Wyllie, S.G. and Leach, D.N. 1992. Sulfur-containing compounds in the aroma volatiles of melons (Cucumis melo). J. Agric. Food Chem. 40:253-256. 